\title{
Estimation of long term exposure to mixed solvents from questionnaire data: a tool for epidemiological investigations
}

\author{
ANNE T FIDLER, E L BAKER, R E LETZ \\ From the Occupational Health Program, Harvard School of Public Health, Boston, MA 02115, USA
}

ABSTRACT Quantifying the exposure of construction painters to mixed organic solvents is difficult in the face of a lack of industrial hygiene data, the heterogeneity of the solvents used, and the variability in work practices which influences the amount of solvents to which a worker is actually exposed. This report describes an attempt to derive an estimate of airborne solvent exposure using questionnaire responses in a population of construction and maintenance painters. This exposure index (EI) is a weighted average of the total number of gallons used a year minus the fraction which would be absorbed by a respirator, where the weights are based on the method of application (spraying, rolling, brushing) and the presence of ventilation (per cent time inside $v$ outside). An analysis performed to determine the sensitivity of the EI to variations in the values chosen for several parameters showed that the index is relatively insensitive to the underlying assumptions that we have used. One component of the EI (self report of hours worked) correlated well with union payroll records. The EI appears to provide a useful relative (not absolute) estimate of airborne exposure to organic solvent mixtures which may be used as a dose surrogate in epidemiological investigations.

In construction and maintenance painting coatings are applied to interiors and exteriors of commercial and industrial buildings, as well as other structures such as tanks, vessels, and bridges. In 1977 there were in the United States about 450000 union and nonunion workers employed in this occupation, applying 8.6 billion gallons of paint composed of over 3000 different substances, ${ }^{1} 95 \%$ of which are listed in NIOSH's Registry of Toxic Effects of Chemical Substances. ${ }^{2}$ Most construction painters use a wide variety of these paints throughout their working lives.

The composition of paints has changed significantly over the years, causing a change in the nature of toxic exposures to those who work with these substances. By the 1960s, oil based paints had largely been replaced by those containing alkyd resins

Present address: Division of Surveillance, Hazard Evaluations, and Field Studies, National Institute for Occupational Safety and Health, Cincinnati, OH 45226.

Accepted 14 April 1986 which, while of low toxicity in themselves, require a much higher relative solvent composition (up to $50 \%$ of the paint product). Though the popularity of water based latex paints has increased dramatically over the past 15 to 20 years, solvent paints are still widely used. About a half to a third of solvents produced in the United States are used in manufacturing surface coatings $^{3}$ (M Guilleman, at international conference on organic solvent toxicity, Stockholm, Sweden, 1984).

Solvent based paints consist of three components: (1) a vehicle, including solvents and resins used as binders; (2) a filler, including pigments and extenders; and (3) additives, including driers, biocidal compounds, and stabilisers. Each of these components may provide a hazardous exposure to those who work with paints. Of major concern are industrial organic solvents, many of which have been shown adversely to affect the functioning of the central nervous systemn (table 1). Several epidemiological studies have focused on workers in a variety of painting operations, as these workers experience a potentially hazardous exposure to many different solvents. Indus- 
Table 1 Partial list of paint solvents/thinners

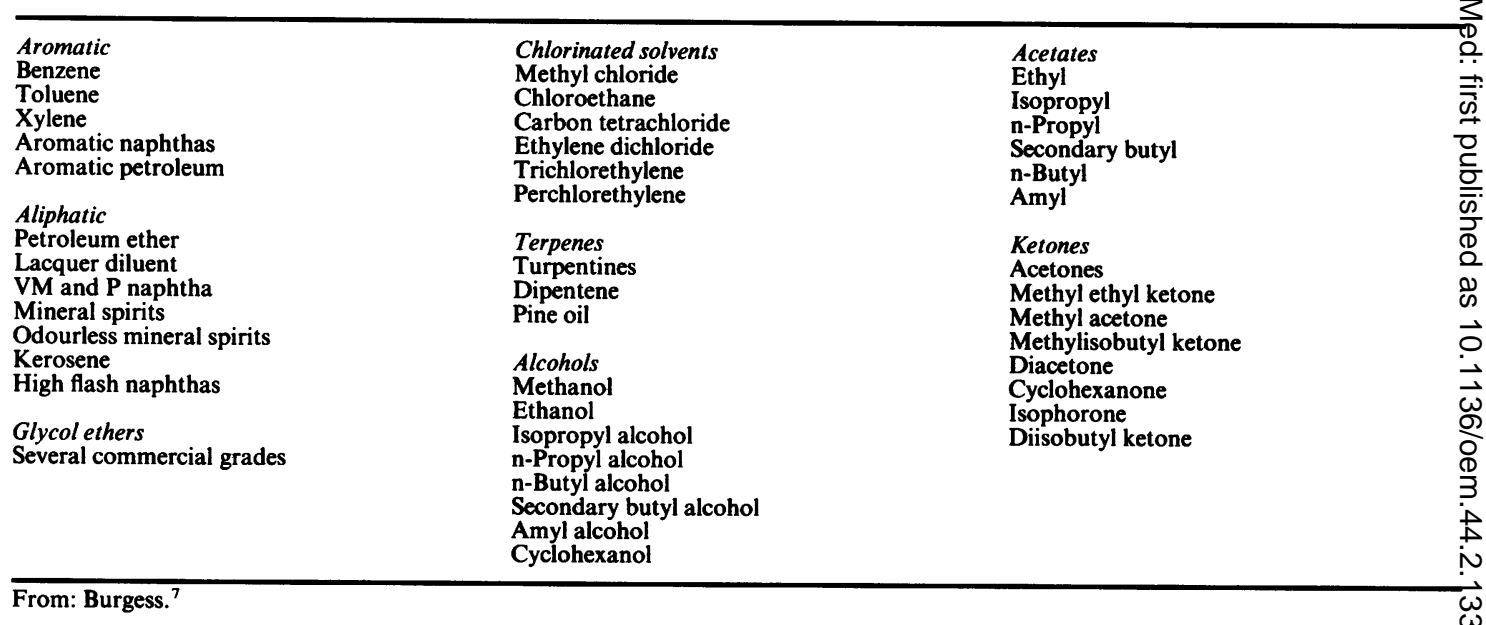

trial paints used in the past contained as many as eight or ten different solvents, whereas most formulations in use today contain four or fewer. ${ }^{4}$ The aliphatic and aromatic solvents are the most common in solvent based paints and in uses that require more expensive oxygenated solvents (alcohols, ketones, and ester/ether) an equal amount of hydrocarbons is usually included. ${ }^{3}$ The aromatics, although less effective than the aliphatics, have been decreasing in use because of their greater toxicity.

\section{Modifying factors of solvent exposure}

The inhaled dose of solvents - that is, the amount of vapour inhaled that ultimately reaches the target organs-is dependent on several physiological parameters. These include pulmonary ventilation rate, diffusion of the solvent through the alveolocapillary and tissue membranes, and solubility of the solvent in blood and tissues. ${ }^{5}$ Solvents may also enter the bloodstream by absorption through the skin. There, individual differences in skin permeability and protection can also affect the total body dose.

The total inhalation exposure to organic solvents generated by workers during painting operations is modified by several factors pertaining to work practices and working conditions. The use of a respirator is an important factor, both because of its potentially large influence in reducing the amount of solvent actually absorbed and because the wearing of respirators varies considerably and non-randomly over a population of painters. Spray painters (with the heaviest total exposure) often wear respirators almost all the time, thus reducing their effect exposure so that it approaches that of those who apply paint with a brush or roller and who have a much lower total exposure but do not wear respirators. Several types of $\rightarrow$ respirators are currently in use, including dust masks, 7 single and double cartridge, and airline or airhood $\mathbb{0}$ respirators. Because they offer no protection against solvent vapours, dusts masks should be considered as conveying no protection at all.

The amount of protection afforded by a respiratgr ${ }^{\infty}$ to an individual is its "protection factor" (PE, defined as:

$\mathrm{PF}=\left[1-\frac{\begin{array}{c}\text { Components analysed } \\ \text { from in mask sample }\end{array}}{\begin{array}{l}\text { Components analysed } \\ \text { from ambient sample }\end{array}}\right]$

Thus the PF is the percentage of the solvent that is absorbed by the respirator. A NIOSH report which evaluated a large number of respirators and working $\frac{\mathbb{D}}{3}$ conditions in paint spraying operations ${ }^{6}$ provides estimates of solvent protection factors. The type and 3 . condition of the respirator, as well as its fit, greatly influence the protection factor an individual will 3 experience. The average PF afforded by cartridge 0 respirators was approximately $65 \%$, whereas the $\mathrm{PF}^{\supset}$ for air supplied respirators was approximately $90 \%$.

Another problem in estimating an "average inhalation exposure" in painting operations is the of inherent difference in exposure generated by different $N$ methods of paint application: spraying, rolling, and N brushing. During processes in which the paint is $\mathrm{\omega}_{\sigma}^{\omega}$ flowed on to the surface, as in rolling and brushing, $a$ painter is exposed to the solvent as it evaporates from the painted surface. Spraying, however, which produces an atomisation of the paint produces an exposure to both the solvent and the paint mist. The 
increase in exposure from spraying reflects the amount of overspray and rebound that occurs. Depending on the method of spraying and the type of surface being painted, the degree of overspray can range from $5 \%$ to $90 \%{ }^{7}$ Because of this variability, it is difficult to estimate the difference in magnitude of exposure that would result from the use of the same amount of paint in the three types of operations, although it is agreed that by far the greatest exposure occurs during spraying operations.

In addition to the use of respirators and the differential exposure generated by the different methods of application, the presence of ventilation is also a factor of interest because of its influence on the effective dose of solvents to an individual. A recent study by Riala et al reported industrial hygiene evaluations of 92 work stations at 18 sites during maintenance painting operations. ${ }^{8}$ Solvent naphtha concentrations were determined by alkyd and urethane painting performed at these sites, stratified by method of application, room size, and presence or absence of ventilation. Ventilation was considered to be present if there was either mechanical or natural draft ventilation and was found to produce a $50-90 \%$ decrease in the ambient air solvent concentration across different application methods and room sizes.

\section{Estimation of exposure: limitations of epidemiological studies}

The epidemiological evaluation of the neurobehavioural effects of solvents on painters is complicated not only by the difficulty in measuring the effect of the exposure but also by the exposure itself. Solvent paints are a heterogeneous group of chemicals that often defy attempts to define or even categorise, often because of the lack of informative labelling of containers and the failure of paint manufacturers to disclose the components of the materials. In addition, a large percentage of construction workers are not employed for a substantial period by one employer; rather, they may work for a few days or a few months on a job and then move to another. Therefore, the nature and amounts of paint substances to which they are exposed vary greatly. In addition, because many painters work on transient construction sites the collection of valid hygiene monitoring data is seldom feasible.

Another potential source of documentation of exposure, biological monitoring, may be used if the type of solvent to which the worker is exposed is known. For example, exposure to toluene may be monitored by urinary hippuric acid levels and styrene by mandelic acid levels. ${ }^{9}$ Paints usually contain mixtures of organic solvents, however, many of which have no biological marker. Painters may use several types of paints, even within the same day. Furthermore, biological measurements reflect only current exposures and cannot be used to assess past exposure.

Because estimating the level as well as the type of exposure over a working lifetime is difficult many studies have used the duration of exposure as the sole estimate of exposure. ${ }^{10-15}$ This measure ignores the intensity and type of exposure. Furthermore, since the duration of exposure is highly correlated with age and since the occurrence of neurobehavioural impairment increases with age, it is often difficult to distinguish solvent effects from the effects of aging. Furthermore, the use of duration as the sole measure of exposure is based on the assumption that the toxic effects of solvents are a function of cumulative exposure. Other models which use more precise estimates of exposure, incorporating terms for exposure intensity, duration, and work practices, are potentially more useful in epidemiological studies.

\section{Rationale of exposure estimation technique}

Frequently the only source of information regarding exposure in a population is a questionnaire completed by the worker. Recently, Mikkelsen and Browne developed a measure of estimated solvent exposure based on extended personal interviews regarding duration of exposure, application rates, materials used, respirator use, and work conditions, including ventilation (reported at Stockholm conference, 1984). The practicalities of a large field study, taking place either at the workplace on "company time" or at another site in the subjects' spare time, preclude the use of such a time consuming instrument.

In evaluating solvent exposed industrial workers Gregersen et al defined exposure on an 11 point scale weighted by specific criteria according to different places of work. ${ }^{16}$ These criteria included duration of exposure, evaporation rates, ventilation, skin absorption rates, respirator use, and toxicity of the materials used. This type of exposure index is not directly applicable to the study of construction painters, as it is partially based on industrial hygiene data that are unavailable in this population and it cannot easily accommodate the variability in exposure and work conditions experienced by painters. Using their index of exposure, the dose response relation was observed with measures of intellectual and peripheral nerve function.

In an earlier epidemiological study of construction painters we evaluated the questionnaire approach to obtaining a history of solvent exposure. ${ }^{17}$ An exposure questionnaire was developed to determine hours worked as a painter, methods and rates of application, respiratory protection, and ventilation. Union payroll records were reviewed to obtain an 
objective estimate of time worked and the nature of the job. In that study we found that we could obtain answers to exposure related questions and reports of hours worked which correlated well $(r=0.75)$ with similar data obtained from union payroll records. Thus we think that self reported work rates are an accurate estimate of actual hours worked and are suitable for use in calculating exposure variables.

The aim of the present study was to generate a reliable estimate of long term inhalation (or airborne) exposure to solvents from questionnaire data obtained from a group of construction painters.

\section{Methods}

In April 1984 a health survey was undertaken of 118 painters from the Boston District Council of the International Brotherhood of Painters and Allied Trades (IBPAT). A solvent exposure history questionnaire, derived partially from one developed by IBPAT and modified in our earlier study, ${ }^{17}$ was administered to all participants. The subjects, including current and former full time and part time painters, were asked to estimate their average application rates, percentage of time spent actually painting, and respirator use, both over the past year and during their working lifetimes.

A set of computerised tests of neurobehavioural function, chest $x$ ray, and pulmonary function tests were also administered to the painters and to 45 unexposed dry wall tapers. The results of these examinations will be reported elsewhere.

\section{CALCULATION OF EXPOSURE INDEX}

The inhalation exposure index (EI) provides an estimate of the amount of solvent vapour to which a workers is exposed by inhalation, based on individual reports of work activities, estimates of the effectiveness of two types of respirators worn by painters, assumptions regarding the relative airborne solvent generation rates of three methods of paint application, and an adjustment factor to account for the impact of workplace ventilation. Individuals pro-
Table 3 Estimates of solvent exposure among different types of painters*

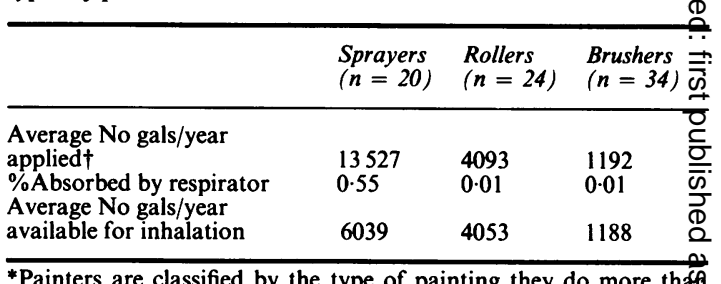

*Painters are classified by the type of painting they do more thaff $50 \%$ of the time.

†All estimates refer to painters' preferred method of application $\vec{O}$ that is, estimates for sprayers pertain only to their exposure while spraying.

vided information on paint use rates, by applicatio method, percentage of work time spent in paint appli cation, and amount of time worked using solvent paints in the past month, year, and over a lifetime. Details of respirator use and the availability of ventiw lation were also obtained where possible.

The general form of our exposure index (EI) is given by:

$$
E I_{j}=\sum_{i} \sum_{r} \sum_{m}\left(T_{j} F_{m r i j}\right)\left(R_{m j} E_{m}\right)\left(\left(1-R_{r}\right) V_{i}\right)
$$

where:

EI is the exposure index

$\mathrm{j}$ is the $\mathrm{jth}$ individual

$\mathrm{i}$ is outdoor/indoor $(1=$ indoor; $2=$ outdoor $)$

$r$ is respirator type $(1=$ none or dust; $2=$ cartridg

$$
3=\text { airline) }
$$

$\mathrm{m}$ is method of paint application $\left(1=\right.$ spray; $2=\operatorname{rol} \frac{\mathbb{R}}{\mathrm{B}}$

$$
3=\text { brush) }
$$

$T$ is time spent painting (hours)

$F$ is the fraction of time

$\mathrm{R}$ is paint application rate (gallons/hour)

$E$ is a relative vapour emission factor for each method

$$
(2 \cdot 5,1 \cdot 25,1 \text {, respectively) }
$$

$P$ is a protection factor for each type of respirator $(0,0 \cdot 65,0 \cdot 90$, respectively)

\begin{tabular}{|c|c|c|c|c|}
\hline \multirow[b]{2}{*}{ Exposure index } & \multicolumn{2}{|c|}{ Respirator $P F$} & \multirow{2}{*}{$\begin{array}{l}\text { Method } \\
\text { Spray:roll:brush }\end{array}$} & \multirow{2}{*}{$\begin{array}{l}\text { Ventilation } \\
\text { Inside:outside }\end{array}$} \\
\hline & Air & Cartridge & & \\
\hline $\begin{array}{l}1 \\
2 \\
3 \\
4 \\
5 \\
6 \\
7 \\
8\end{array}$ & $\begin{array}{l}0.90 \\
0.90 \\
0.90 \\
0.90 \\
0.90 \\
0.70 \\
0.70 \\
0.70\end{array}$ & $\begin{array}{l}0.65 \\
0.65 \\
0.65 \\
0.65 \\
0.65 \\
0.50 \\
0.50 \\
0.50\end{array}$ & $\begin{array}{l}10: 5: 4 \\
10: 5: 4 \\
10: 5: 4 \\
10: 7: 6 \\
10: 4: 2 \\
10: 5: 4 \\
10: 7: 6 \\
10: 4: 2\end{array}$ & $\begin{array}{l}5: 1 \\
9: 1 \\
1: 1 \\
1: 1 \\
1: 1 \\
1: 1 \\
1: 1 \\
1: 1\end{array}$ \\
\hline
\end{tabular}

$\mathrm{V}$ is a ventilation factor relative to outdoors ( 1 , respectively)

Table 2 Exposure indices used in sensitivity analysis 

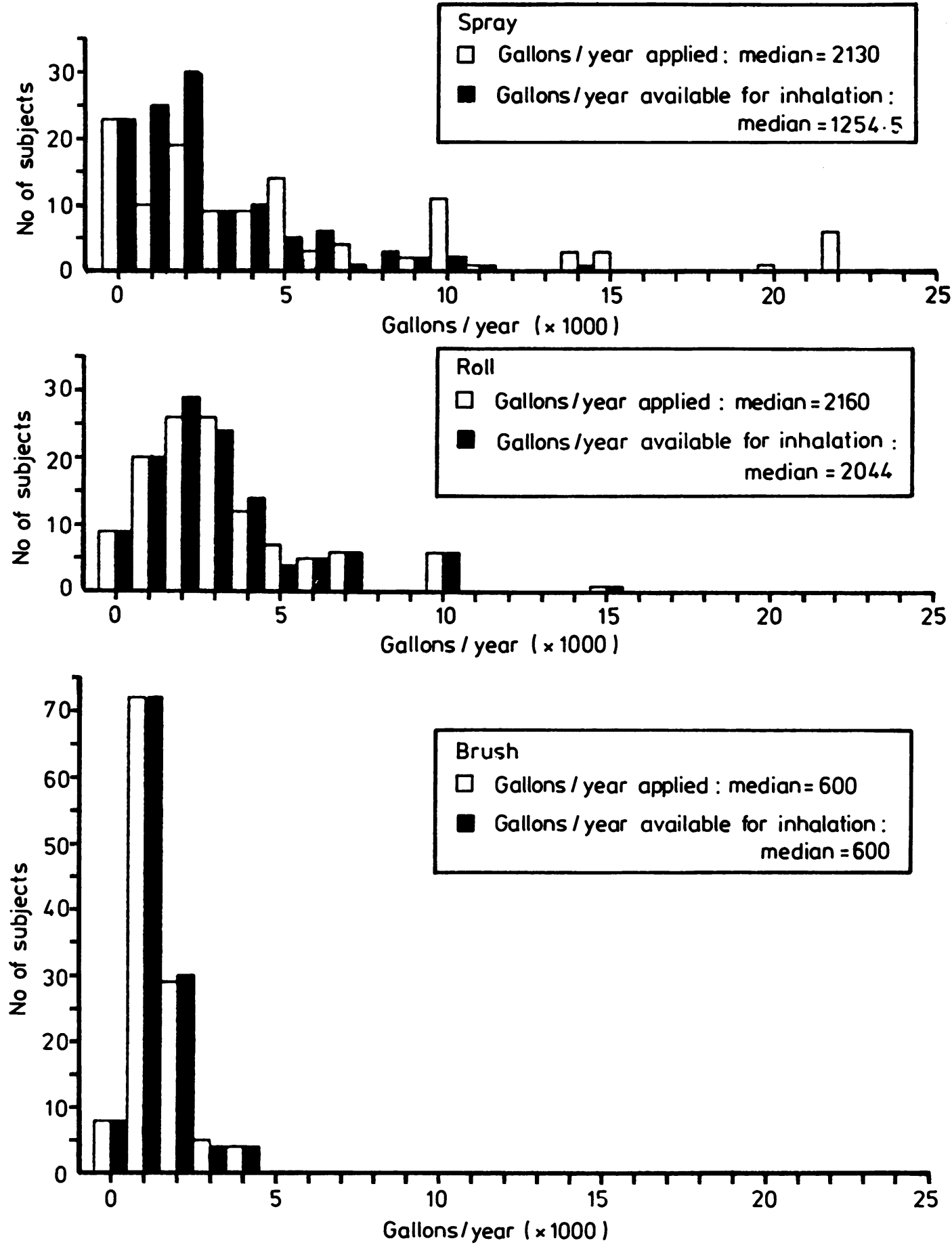

Fig 1 Distributions of total paint applied and paint available for inhalation (total paint minus fraction absorbed by respirator) for each of three application methods (spray, roll, brush). 
This expression is a time weighted average, with the first two parameters, $T$ and $F$, providing the time component, the second two, $\mathrm{R}$ and $\mathrm{E}$, related to source strength, and the last two, $\mathrm{P}$ and $\mathrm{V}$, providing for source modification. Reports from each painter provide estimates of the $T, F$, and $R$ parameters for each individual, while overall estimates of the $E, P$, and $\mathrm{V}$ parameters have been derived from previous hygiene data.

Arriving at a weighting scheme for the method of paint application is made difficult by the scarcity of hygiene data reported for different types of painting operations. Two separate estimates made by experienced industrial hygienists (W A Burgess and T $J$ Smith) gave relative exposure for spraying:rolling:brushing of 10:7:6 and 10:4:2. On this basis the weighting scheme used in the exposure index was 10:5:4.

Based on reports, ${ }^{6}$ estimates of average protection factors (PFs) were chosen as $\mathbf{0 . 6 5}$ for cartridge and 0.90 for air supplied respirators.

No direct estimation of ventilation was available in the present study but workers reported the average amount of time during which they worked inside or outside. The scheme used weighted the relative contribution of indoor and outdoor painting as 5 to 1 , which is compatible with other hygiene surveys. ${ }^{8}$

For each individual the exposure index generated is a weighted average of the number of gallons a year of solvent based paints applied. No judgement of the amount of solvent actually absorbed is made. Because the $E, P$, and $V$ parameters are relative, the units of the exposure index are equivalent gallons brushed outdoors without a respirator. Although the exposure index may be calculated to estimate the intensity of exposure during any period, we have chosen to calculate it for the entire working lifetime as a painter; subsequent analyses are based on this lifetime exposure index.

\section{SENSITIVITY ANALYSIS}

The sensitivity of the exposure index to variations in the values chosen for respirator protection factors or the weighting schemes was investigated by varying the values used for these parameters and comparing the resulting indices, using simple correlation analysi and stratified analyses. The values were varied as fot lows:

Respirator PF: cartridge $=0.65$ and 0.50 airline $=0.90$ and 0.70

Weighting schemes:

Spray:roller:brush $=10: 4: 2 ; 10: 5: 4 ; 10: 7: 6 ; 1: 1: 1$ Inside:outside $=2: 1 ; 5: 1 ; 9: 1 ; 1: 1$

Eight indices representing the range of values of the possible combinations of these terms were selected and used in subsequent analyses (table 2).

\section{Results}

All 118 painters completed work history question naires and were classified by the method of applicas tion which they had used for more than half the time There were $20(16.9 \%)$ sprayers, $24(24.3 \%)$ rollers $34(28.8 \%)$ brushers, and $40(33.3 \%)$ who used no sinct gle method more than half the time. The sprayers ha\& a mean age of 39.8 years (SD 10.0), 10.6 (SD 2.1) years of school, and a Hollingshead Index (parenta SES) (HI) of 53.5 (SD 12.6). Rollers had a mean age of 46.1 years (SD 11.4), 10.8 (SD 2.6) years of schoot and an HI of 56.8 (SD 8.4). The brushers' mean age was 46.5 years (SD 11.7), with 11.7 (SD 2.5) years of school, and an HI of $55 \cdot 6$ (SD 12.2). The 40 remaingng painters had a mean age of 37.7 years (SD 9.9), (SD 2.1) years of school, and an HI of 52.0 (SD 1 lob The sprayers consumed more alcohol than the ot painters: 19.4 drinks a week (SD 27.5) as opposed t 11.0 (SD 11.8), 13.5 (SD 14.2), and 9.1 (SD 11.8) foô rollers, brushers, and others, respectively.

In this population spray painters applied abou $\overrightarrow{\overrightarrow{6}}$ four to ten times as many gallons as rollers or brush $\$$ ers (table 3 ). On average, however, more than $50 \%$ of their total breathing zone vapour was absorbed b. respirators, whereas virtually all of the solvent vapoug generated by rollers and brushers is available fo $\$$ inhalation because of the lack of respiratory proteco tion. Hence, this four to tenfold increase in total. exposure is reduced to a less than two to fivefol $\$$ increase in inhalable exposure (table 3). All types of painters generally wear respirators when spraying. $ᄋ$

Table 4 Correlation matrix of exposure indices resulting from variations in parameters

\begin{tabular}{|c|c|c|c|c|c|c|c|c|c|}
\hline & & $E I I$ & $E I 2$ & EI 3 & $E I 4$ & EI 5 & EI6 & $E I 7$ & $E I 8$ \\
\hline $\begin{array}{l}\text { EI } 1 \\
\text { EI } 2 \\
\text { EI } 3 \\
\text { EI } 4 \\
\text { EI } 5 \\
\text { EI } 6 \\
\text { EI } 7 \\
\text { EI } 8\end{array}$ & . & 1.00 & $\begin{array}{l}0.99 \\
1.00\end{array}$ & $\begin{array}{l}0.93 \\
0.92 \\
1.00\end{array}$ & $\begin{array}{l}0.92 \\
0.90 \\
0.99 \\
1.00\end{array}$ & $\begin{array}{l}0.93 \\
0.92 \\
0.99 \\
0.97 \\
1.00\end{array}$ & $\begin{array}{l}0.92 \\
0.90 \\
0.98 \\
0.97 \\
0.98 \\
1.00\end{array}$ & $\begin{array}{l}0.91 \\
0.90 \\
0.99 \\
0.99 \\
0.97 \\
0.99 \\
1.00\end{array}$ & $\begin{array}{l}0.91 \\
0.89 \\
0.97 \\
0.94 \\
0.98 \\
0.99 \\
0.98 \\
1.00\end{array}$ \\
\hline
\end{tabular}


Table 5 Exposure levels of painters classified by three variations of the exposure limit

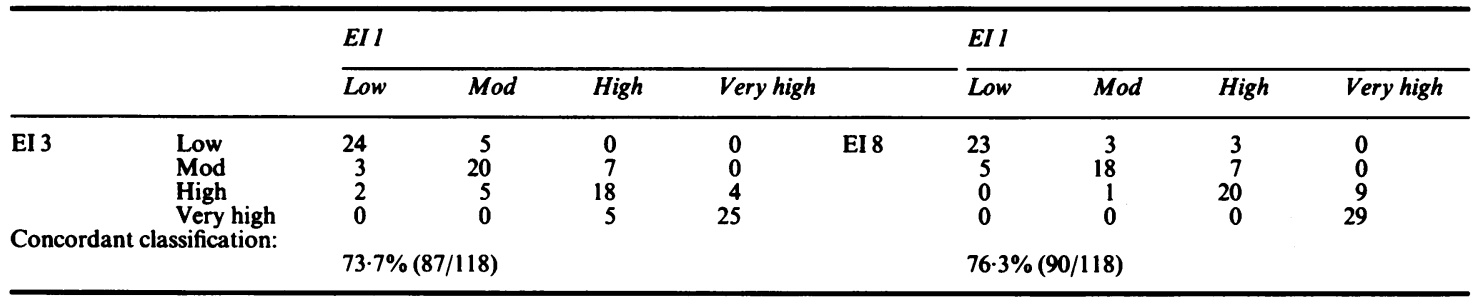

The impact of respirator use is more clearly seen when comparing distributions of individual paint use rates with those of individual inhalable paint amounts. In spray painters the skewed distribution of paint use is significantly changed when respirator use is taken into account (fig 1). The distribution for paint use and inhalable paint level are similar for rollers and brushers.

The eight different exposure indices (table 2) created to evaluate the sensitivity of the index that was selected for final analysis (EI 1) to variations in component terms were highly correlated (table 4). In particular, EI 1 was highly correlated with all other terms $(r=0.91-0.99)$ indicating close relative ranking ability between the indices. Stratified analyses comparing the categorisation of exposure using different indices was comparable among the different values chosen (table 2) for the eight indices. For example, $73.7 \%$ of 118 painters were identically classified using either EI 1 or EI 3; only two individuals $(1.7 \%)$ were reclassified by more than one category. Even higher agreement was noted, $76.3 \%$, between indices 1 and 8 , with no one reclassified by more than one category (table 5).

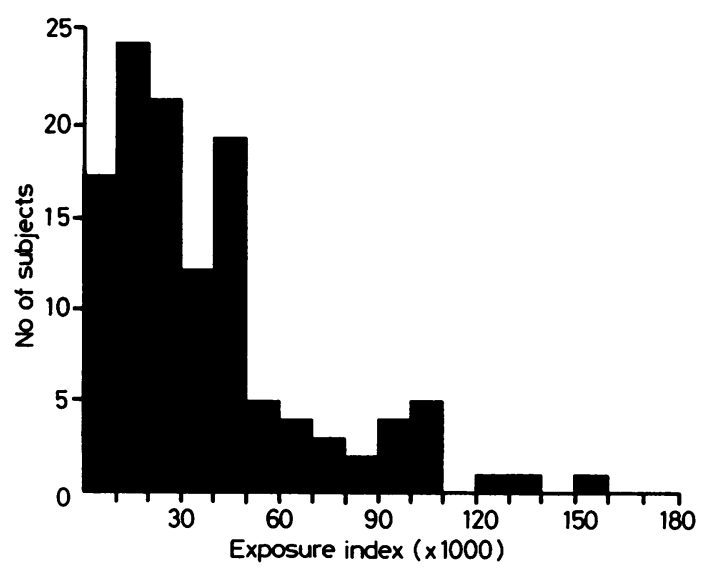

Fig 2 Frequency distribution of exposure index $(n=118)$. (See text for derivation of EI.)
The exposure index for all 118 painters (fig 2) ranged from $554 \cdot 2$ to 32684.2 (median: 604 ). The exposure index was compared among the different types of painters. As expected, sprayers have the highest value, followed by rollers and brushers (table 6).

The exposure index correlated moderately well with its component parameters (table 7). None was obviously dominant or irrelevant in contributing to the index. Furthermore, the lifetime exposure index was not correlated with the number of years worked as a painter $(r=0.01)$. Simply using one of the component variables only (percentage time spent spraying, for example) as an index of exposure, while appealing in its simplicity and ease of use, does result in considerable disagreement in exposure group classification; there is only a $44.9 \%$ agreement with ten subjects $(8 \cdot 5 \%)$ reclassified by more than one category (table 8 )

By combining information on years of exposure to paints-that is, exposure duration-with the exposure index (a measure of exposure intensity), a

Table 6 Exposure index by type of painter*

\begin{tabular}{lrll}
\hline & No & Median & Range \\
\hline Sprayers & 20 & 59745 & $3643-155078$ \\
Rollers & 24 & 28305 & $6584-86939$ \\
Brushers & 34 & 15699 & $3643-109298$ \\
Mixed & 40 & 29550 & $2632-92720$ \\
Total & 118 & 28994 & $2632-155249$ \\
\hline
\end{tabular}

*Painters are classified by the type of painting they do more than $50 \%$ of the time.

Table 7 Correlation coefficients ( $r$ ) between exposure index and its components

\begin{tabular}{lc}
\hline Component variables & $\begin{array}{l}\text { Correlation } \\
\text { coefficient }\end{array}$ \\
\hline \%Time spraying & 0.59 \\
\%Time rolling & -0.02 \\
\%Time brushing & -0.29 \\
Gals/hour spraying & 0.65 \\
Gals/hour rolling & 0.55 \\
Gals/hour brushing & 0.17 \\
\%Time outside & -0.28 \\
\hline
\end{tabular}


Table 8 Exposure levels of painters classified by exposure index and one of its components (\% time spraying)

\begin{tabular}{|c|c|c|c|c|c|}
\hline & & \multicolumn{4}{|l|}{$E I I$} \\
\hline & & Low & Mod & High & Very high \\
\hline$\%$ Time spraying & $\begin{array}{l}\text { Low } \\
\text { Mod } \\
\text { High } \\
\text { Very high } \\
\text { Concordant }\end{array}$ & $\begin{array}{c}14 \\
9 \\
0 \\
0 \\
0\end{array}$ & $\begin{array}{c}11 \\
15 \\
18 \\
5 \\
\text { ion: } 44\end{array}$ & $\begin{array}{l}2 \\
5 \\
9 \\
9 \\
.9 \%(5\end{array}$ & $\begin{array}{c}2 \\
1 \\
3 \\
15 \\
/ 118)\end{array}$ \\
\hline
\end{tabular}

composite cumulative exposure measure (duration $x$ intensity) is derived (table 9). Although spray painters have worked fewer years than rollers or brushers, their intensity and cumulative exposure level was considerably higher.

\section{Discussion}

The index of long term exposure to mixed organic solvents presented combines information obtained from painters by means of a concise questionnaire with weighting schemes established by reported hygiene evaluations for factors that modify the exposure to an individual. These include respirator use, method of paint application, and presence of ventilation. Sensitivity analysis demonstrates that the exposure index is not unduly sensitive to the assumptions underlying the constituents that reflect these parameters. Because epidemiological studies of construction painters are inherently limited by a lack of objective hygiene data or records of paint use, the only feasible source of information regarding the history of exposure is the individual painter. The exposure index uses this information to yield a useful estimate of the relative ranking of individual exposure to paint solvents.

The validity of the exposure index as a true measure of solvent exposure rests primarily on the issue of self reports of painters of amounts of paints used, application rates, and other measures of exposure.

Table 9 Three measures of lifetime exposure among different types of painters*

\begin{tabular}{|c|c|c|c|}
\hline & $\begin{array}{l}\text { Sprayers } \\
(n=20)\end{array}$ & $\begin{array}{l}\text { Rollers } \\
(n=24)\end{array}$ & $\begin{array}{l}\text { Brushers } \\
(n=34)\end{array}$ \\
\hline $\begin{array}{l}\text { Median years as painter } \\
\text { (duration) }\end{array}$ & 15 & 22 & 22 \\
\hline $\begin{array}{l}\text { Median exposure index } \\
\text { (intensity) }\end{array}$ & 59746 & 28305 & 15698 \\
\hline $\begin{array}{l}\text { Median cumulative exposure } \\
\text { (duration } \times \text { intensity) }\end{array}$ & 522163 & 634467 & 319015 \\
\hline
\end{tabular}

*Painters are classified by the type of painting they do more than $50 \%$ of the time.
Because most of these assess average paint use over working lifetime, it may often be difficult for painte to provide a reliable and accurate estimate. It $\&$ unlikely, however, that there is a systematic difference: in reporting based on health effects of the exposure? since in most instances it is the subclinical effects that are under investigation and are, therefore, not pe ceived by the subjects.

\section{SELECTION OF EXPOSURE MODEL}

As stated previously, proper modelling of exposure must be based on clear assumptions regarding the toxic actions of solvents on the central nervous system. Three potential measures-duration of exposure, intensity of exposure, and cumulatike exposure (duration times intensity)-are presented for the different types of painters (table 9). It may be seen that in this study spray painters have a shorte? mean duration of exposure but a much higher average level of exposure, as defined by the exposure index than either rollers or brushers. Therefore, if duration was chosen as the exposure measure, spray painters would compose a greater proportion of the lower exposure categories whereas a measure of intensit would put them in the higher exposure categorie Likewise, if a cumulative measure were used, then the potentially different effects of duration and intensite would mask each other. Use of a different measurg of intensity, such as an exposure index based on pain done in the past year, rather than a lifetime averige would provide an ability to investigate yet anothe model of the effects of exposure.

Clearly, the key to the investigation of a dos response relation between exposure to organic so vents and neurobehavioural deficits is a valid estima of level of exposure. Because of the unavailability of such an estimate among construction workers, studie have had to rely on the duration of the exposure as surrogate. The exposure index presented here mag provide an alternative which can effectively rank ind viduals by their average long term exposure to mixeg organic solvents.

Though the exposure index provides a stable sum mary measure of the level of solvent exposure, it has several limitations. Differences in paint composition both in type and toxicity of solvents and in percentage composition of solvents, preclude a direct conversion. of the number of gallons to which individuals atce exposed to a quantity of solvent. Also, without futther information regarding the nature of paints use it is not possible to account for the possible corve founding effects of other neurotoxic constituents suc as lead and mercury.

In addition, workers who used solvent paints in the past experienced a somewhat higher exposure thant they have recently because many paints contained 
more solvents per gallon. Older painters, therefore, may show toxic effects that may appear to be due to aging but could in fact be due to their higher previous exposure which is unaccounted for by the exposure index. The expected effect of this problem would appear to be small, however, because the difference in the exposure index that would occur would be relatively minor by comparison with the effect of aging.

Many environmental and occupational conditions present problems similar to those faced when evaluating the exposure of painters; these include lack of hygiene data, mixed exposures, and various job classifications or modes of exposure. The investigation of toxic waste sites and exposure of construction workers to asbestos are examples where an approach similar to the one used here would be helpful in reducing a complex exposure history so that individuals could be ranked in order to investigate dose response relations.

We are grateful to Drs James Ware and Richard Monson who reviewed the manuscript and Mr Rodney Wolford and staff of the International Brotherhood of Painters and Allied Trades for their help in the design of the questionnaire used in the study. This research was supported by the National Institute of Environmental Sciences National Research Service Award 5 T32 ES 07069 from the Harvard School of Public Health.

\section{References}

1 National Paint and Coatings Program. Data bank program. Washington: SRI International, 1978.

2 National Institute for Occupational Safety and Health. Registry of toxic effects of chemical substances. Washington: Department of Health, Education, and Welfare, 1976. (HEW publ No (NIOSH) 76-191.)

3 Mehlman MA, Smart CL. A comparative toxicological evaluation of paint solvents. In: Englund A, Ringen K, Mehlman
MA, eds. Advances in environmental toxicology. Vol II. Occupational health hazards of solvents. Princeton: Princeton Scientific Pubs, Inc, 1982:53-67.

4 Hansen CM. Solvent technology in product development. In: Englund A, Ringen K, Mehlman MA, eds. Advances in environmental toxicology. Vol II. Occupational health hazards of solvents. Princeton: Princeton Scientific Pubs, Inc, 1982:43-52.

5 Astrand I. Uptake of solvents in the blood and tissues of man. A review. Scand J Work Environ Health 1975;1:199-218.

6 Toney CR, Barnhart WL. Performance evaluation of respiratory protective equipment used in spray painting operations. Washington: Department of Health, Education, and Welfare, 1977. (HEW publ No (NIOSH) 76-177.)

7 Burgess WA. Recognition of health hazards in industry. A review of materials and processes. New York: John Wiley and Sons, 1981.

8 Riala R, Kalliokoski P, Pyy L, Wickstrom G. Solvent exposure in construction and maintenance painting. Scand $J$ Work Environ Health 1984;10:263-6.

9 Lauwerys RR. Industrial chemical exposure: guidelines for biological monitoring. Davis, CA: Biomedical Publications, 1983.

10 Hane $\mathrm{M}$, Axelson $\mathrm{O}$, Blume $\mathrm{J}$, et al. Psychological function changes among house painters. Scand $J$ Work Environ Health 1977;3:91-9.

11 Iregren A. Effects of psychological test performance of workers exposed to a single solvent (toluene); a comparison with effects of exposure to a mixture of organic solvents. Neurobehav Toxicol Teratol 1982;4:695-701.

12 Lindstrom K, Martelin T. Personality and long term exposure to organic solvents. Neurobehav Toxicol 1980;2:89-100.

13 Olson BA. Effects of organic solvents on behavioural performance of workers in the paint industry. Neurobehav Toxicol Teratol 1982;4:703-8.

14 Seppalainen AM, Lindstrom K, Martelin T. Neurophysiological and pscyhological picture of solvent poisoning. Am J Ind Med 1980;1:31-42.

15 Harkonen H, Lindstrom K, Seppalainen AM, et al. Exposureresponse relationship between styrene exposure and central nervous system functions. Scand $J$ Work Environ Health 1978;4:53-9.

16 Gregersen P, Angelso B, Nielsen TE, et al. Neurotoxic effects of organic solvents in exposed workers: an occupational, neuropsychological, and neurological investigation. Am J Ind Med 1984;5:201-25.

17 Baker EL, Letz RE, Fidler AT. A computer-administered neurobehavioural evaluation system for occupational and environmental epidemiology. Rationale, methodology, and pilot study results. J Occup Med 1985;27:206-12. 